\title{
A Low Cost Microcontroller-based Automated Irrigation System for Two Ethiopian Crops in a Dry Area
}

\author{
Yenenesh Alemu', Tsegaye Mamo ${ }^{1}$, Ashenafi Bezabih ${ }^{1}$, Fekadu Setegn ${ }^{1}$, \\ Jemal Endris ${ }^{1}$ and Taye Girma ${ }^{2}$
}

\author{
${ }^{1}$ Department of Computer Engineering, Microlink Information Technology College, Addis Ababa, Ethiopia \\ ${ }^{2}$ Department of Computer Science, St.Mary's University, P.O. Box: 120611, Addis Ababa, Ethiopia
}

\begin{tabular}{|c|c|}
\hline $\begin{array}{c}\text { Abstract } \\
\text { Maintaining soil water level is a necessary and pre-requisite for optimum crops production. }\end{array}$ & \\
\hline \multirow{12}{*}{$\begin{array}{l}\text { Maintaining soil water level is a necessary and pre-requisite for optimum crops production. } \\
\text { Water is the essential elements for proper growth of crops in its optimum level; however its } \\
\text { excessiveness should be avoided. Since irrigation is a dominant consumer of water, there } \\
\text { must be a system which regulates the level of water use so that the irrigation field is neither } \\
\text { over-irrigated nor under-irrigated. Over time, systems have been implemented towards } \\
\text { realizing this objective and most of them employ micro-controller based irrigation systems. } \\
\text { These systems offer several technological advantages but are unaffordable, bulky, difficult to } \\
\text { maintain and less accepted by the technologically unskilled workers in the rural scenario. The } \\
\text { aim of this paper is to design a simple, easy to install, monitor and indicate the level of soil } \\
\text { moisture that is continuously controlled in order to achieve maximum crops growth and } \\
\text { simultaneously to optimize the available irrigation resources, water and etc. A simple } \\
\text { microcontroller based circuit is used coupled with relay units which control the water pumps. } \\
\text { The use of easily available components reduces the manufacturing and maintenance costs. } \\
\text { This makes the proposed system to be an economical, appropriate and a low maintenance } \\
\text { solution for applications, especially in rural areas and not only for small scale agriculturists but } \\
\text { also large scale too. The physical implementation result of the proposed system and its } \\
\text { simulation result are tested and checked for consistence and correctness. } \\
\text { Copyright@2015 STAR Journal, Wollega University. All Rights Reserved. }\end{array}$} & Received : 03-06-2015 \\
\hline & Revised : :04-09-2015 \\
\hline & Accepted : 23-09-2015 \\
\hline & Keywords: \\
\hline & Microcontroller \\
\hline & ted Irrigation \\
\hline & umidity \\
\hline & Crops \\
\hline & ${ }^{*}$ Corresponding Author: \\
\hline & Taye Girma \\
\hline & \\
\hline & \\
\hline
\end{tabular}

\section{INTRODUCTION}

Irrigation is the artificial use of water to enable the growing crops in areas where there is rainfall shortage and scarcity of water reservoir (Kotaiah Swamy et al., 2013). The ancient Irrigation practice has passed through many different stages over the years with a lot of improvements (Umeh Maryrose et al., 2015). These days the available irrigation system has limitations like leaching off soil nutrients, erosion due to flooding, loss of water from plant surfaces through evaporation, water wastage which can result to water scarcity in drought areas and production of unhealthy crops; but with the new a low cost microcontroller-based automated Irrigation system, all these limitations are avoided (Umeh Maryrose et al., 2015).

The two extreme edges of irrigation is either getting under-watered or over-watered. During under-watered, crops suffer from nutrient deficiencies while during overwatered crops are more susceptible to diseases pressure , are not able to withstand dry spells during dry season and can in some cases even lead to root death through suffocation (Umeh Maryrose et al., 2015). The aim of this paper is to design, simulate and implement a microcontroller based irrigation system for two Ethiopian crops (Haricot Beans and Lentil) to manage underwatered and over-watered instant during crops production
(Frehiwot Mulugeta, 2009 and Frehiwot Mulugeta, 2010). The system will help in saving money and water and at the same time increasing crops production. The automated irrigation system is controlled using microcontroller and programmed via the microcontroller to give interrupt signal to the irrigation system (drip, sprinkler, ditch etc.) depending on the soil moisture levels. The soil moisture/ humidity levels are checked using soil moisture sensor. Whenever there is a change in moisture/ humidity in the soil this sensor senses the change and gives an interrupt signal to the microcontroller and thus the watering system is activated or deactivated.

The microcontroller based irrigation system basically consists of the microcontroller, the soil humidity sensor, the keypad, LCD and water pump. The soil humidity sensor staked into the soil during installation and it measures the humidity of the soil, such that once the soil becomes dry or saturated based on the crop type, the sensor sends a signal to the microcontroller by which it takes subsequent action.

The LCD displays every process going on and actions taken in the system, from the initialization to monitoring and to pumping water in to the soil or not. 


\section{Yenenesh Alemu et alo,}

Figure 1 shows the basic building blocks of the entire system. The left hand side is the input module, the right hand side is the output module and the centre is the
Sci. Technol. Arts Res. J., July-Sep 2015, 4(3): 192-196

control system. The input module consists of keypad and humidity sensor, which are responsible for inputting data to the control system.

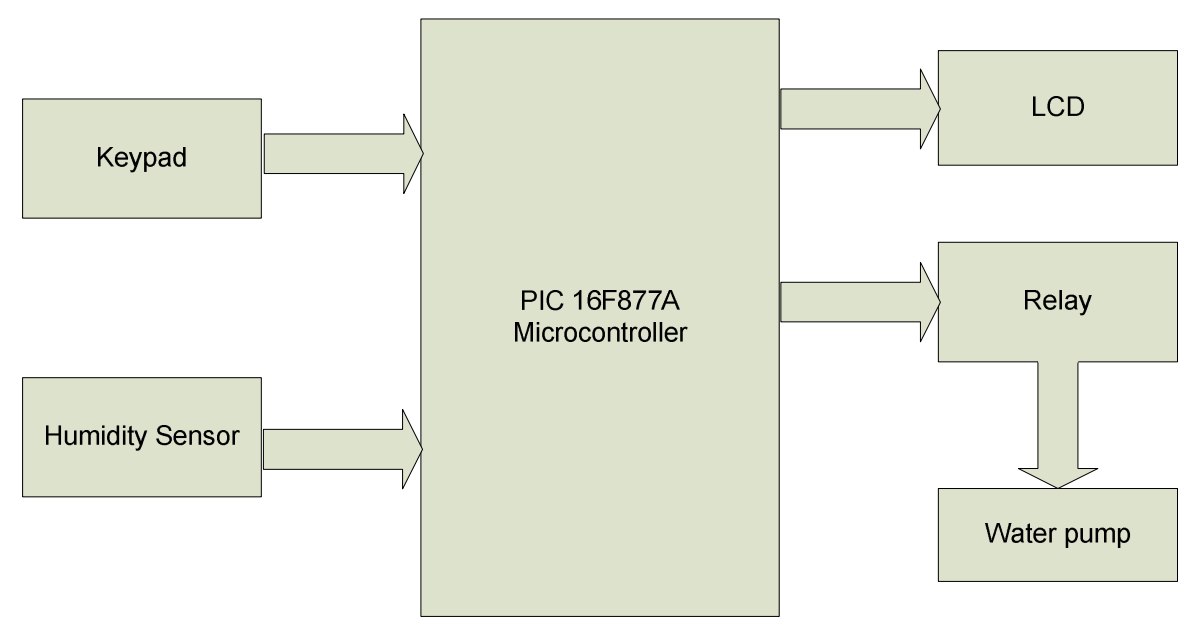

Figure 1: Block diagram for microcontroller based automated irrigation system

Whereas, the output module consists of LCD and water pump driven by relay. This module is responsible to monitor moisture or humidity levels in the soil and switch ON/OFF the watering system based on the comparison result of predefined and current reading value of moisture level by the sensors. The LCD is responsible to display moisture or humidity level by sensors and ongoing processes and actions taken by microcontroller.

\section{MATERIALS AND METHODS}

\section{Materials}

The manual irrigation systems have a difficulty of providing healthy water balance, which actually means, unable to control and monitor the amount of water released into the farming area. Such a system increases the cost of man power, water resources and decreases crop production. Therefore, to enhance the efficiency of a conventional irrigation system the authors proposed a microcontroller based automated irrigation system with optimized cost. In order to build a microcontroller based automated irrigation system for the two Ethiopian crops in dry area, the following hardware and software resources are required:

- Microcontroller: the main components of the system that controls other devices to check for the moisture content of the soil and the release of water. It continuously checks the pins from where it receives the signal from the sensor. When it detects there is less content of moisture in the soil then it sends a signal to the pin that connect the microcontroller and the relay.

- LCD Screen: LCD (Liquid Crystal Display) displays every process going on in the system, from initializing to the monitoring and to the pumping (LCD Module, 2012).

- Keypad: It gives the option to the user to select from the two crops. The user will have three option; first if the user press key 1 from the keypad it implies that the user is going to grow Haricot bean, second if the user press key 2 it shows that the user is going to grow Lentil, third if the user press key other than key 1 or key 2 the system displays an error message.
- Soil Moisture Sensor: it senses the moisture content of the soil and sends signals to the microcontroller to act accordingly. The depth to which the sensor buried depends on where the system is used (Pasha and Yogesha, 2014).

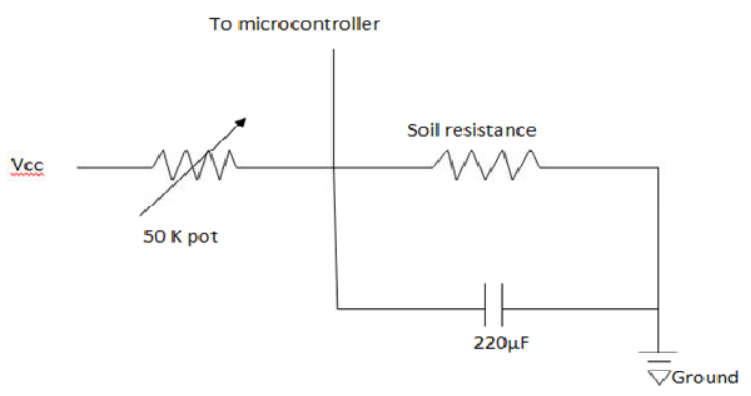

Figure 2: Internal circuit of soil moisture sensor (Adopted from Pasha and Yogesha, 2014)

- Water Pump: it sucks and pumps the water from the water tank to the farm area

- Power Source: A 220 volt AC power supply input is given to the transformer. This voltage is steps down into 12V AC output and converts into 12V DC voltage by the rectifier. And it is fed to 7812 and 7805 regulators. It is then distributed to all the driver and relay circuits. $5 \mathrm{~V}$ is given to the microcontroller and to LCD used in the system.

- Relay: connects the microcontroller and the water pump and acts as switch that switches on/ off of the watering system (Shiraz Pasha and Yogesha, 2014).

- Proteus (for hardware circuit simulation)

- MPLAB IDE and high tech compiler (for programming code using $C$ Language)

\section{Methods}

The continuous increasing demand of crops type in dry areas of Ethiopia (Semera, 2010) requires the rapid improvement in crops production technology to increase the production periods. In these areas of Ethiopia there is significant lack of rains and scarcity of land reservoir 
Yenenesh Alemu et alo,

water and this is what this paper is going to deal with to improve the efficiency of available water use. The paper follows the following procedures to design, simulate and implement a microcontroller based automated irrigation systems are listed below :

- Identifying the Requirements

- $\quad$ Software Requirement

- Hardware Requirement

- $\quad$ Setting the Specification
Sci. Technol. Arts Res. J., July-Sep 2015, 4(3): 192-196

- Designing the System

- Simulating and testing the System

- Physical Implementation of the simulated System

- Testing the physical implementation of the system

The flow diagram for the microcontroller based automated irrigation system for the two Ethiopian crops in the dry area is given as follow:

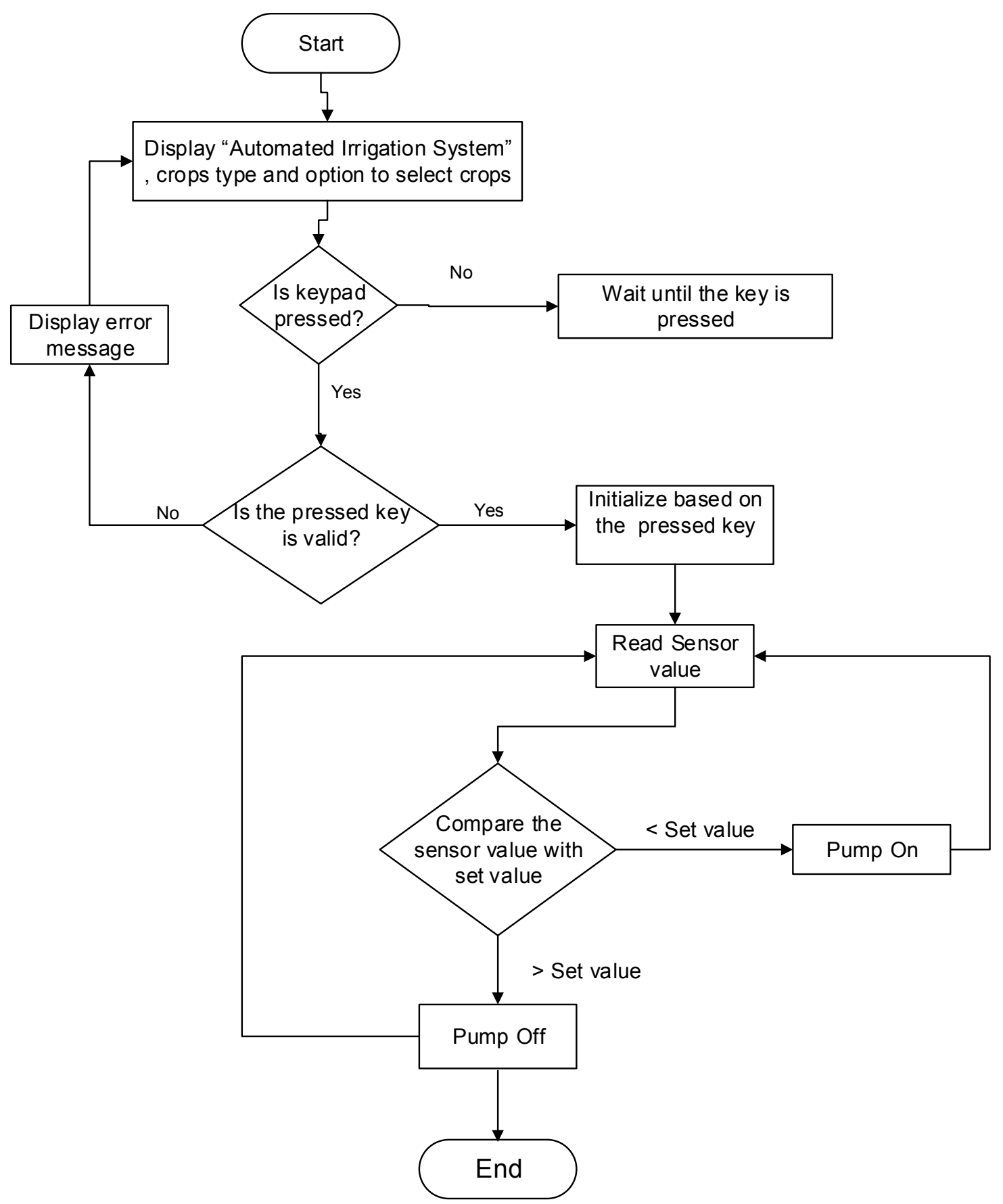

Figure 3: Flow diagram for the microcontroller based irrigation system 
The equivalent Pseudo code for the system flow diagram is given as follows:

1. Initialization

2. Display Automated Irrigation System

3. Display Crop type and gives option to the user to select the crop type

4. Users press the key pad to select crops of interest

5. If (wrong key)

System displays an error message and resume to 4 Else

System initialize based on the pressed key

6. System checks the soil humidity by using humidity sensor

7. If (sensor Reading value < Pre-defined Value)

\{

System turns $\mathbf{O N}$ the water pump

Continuously checks the sensor reading value

\}

Else

System turns OFF the water pump and checks the sensor value

8. End

\section{RESULT AND DISCUSSION}

The microcontroller based automated irrigation system is designed to test the system through simulation using PIC16F877A microcontroller, potentiometer, LCD to display from initialization then the monitoring and finally to the pumping (Figure 4). Keypad is used to select one crop from the two and one relay to switch on/off the motor. Five resistors are used in the system for voltage drops. The simulation using proteus version 7.6 first display the title "Automated Irrigation System", then the type of the two crops on the LCD display. The system is tested for both crops type by increasing and decreasing the values of the potentiometer. This time the value on the LCD varies accordingly. The physical implementation of the system represented in the figure 5 .

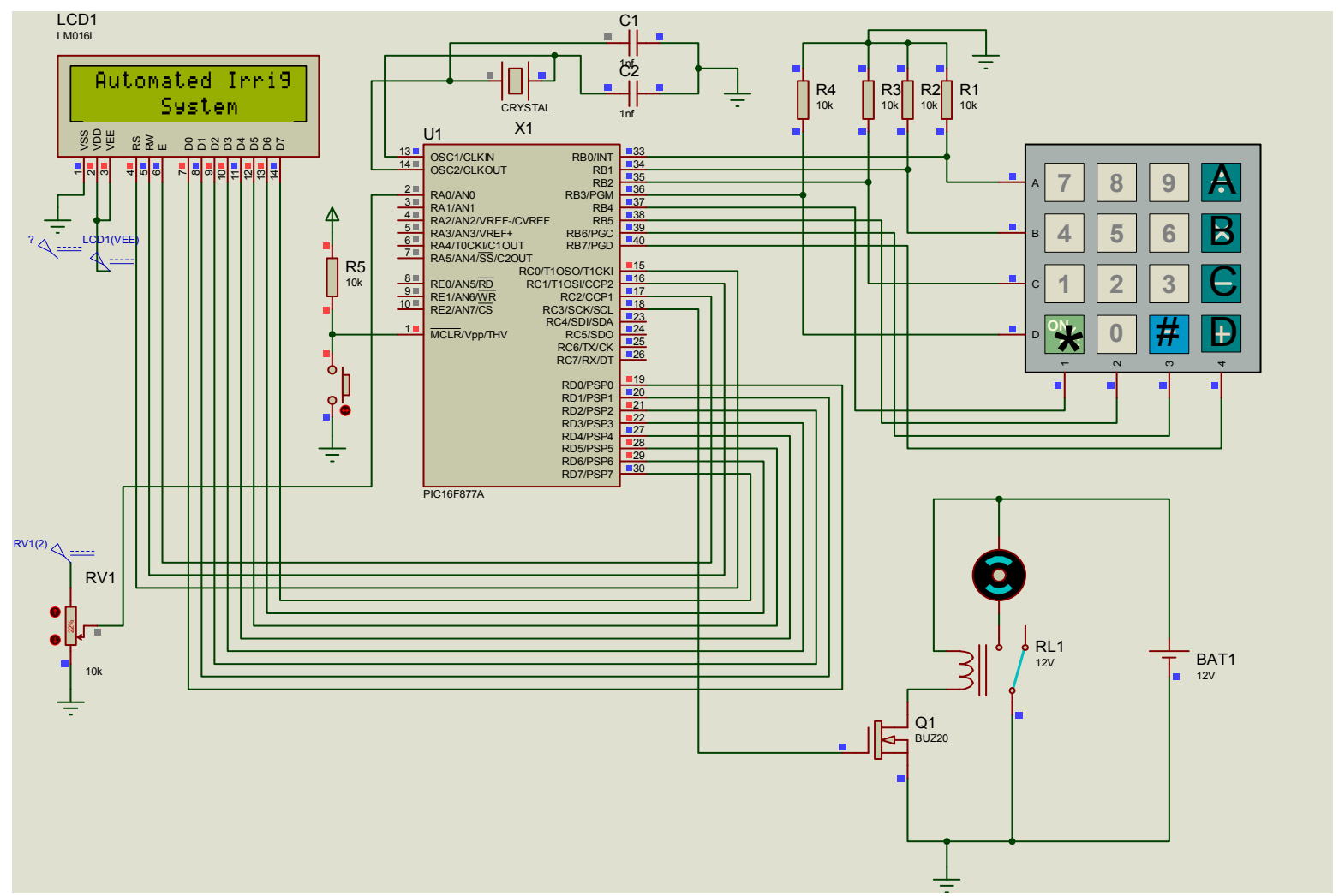

Figure 4: Simulation circuit of the microcontroller-based irrigation system 


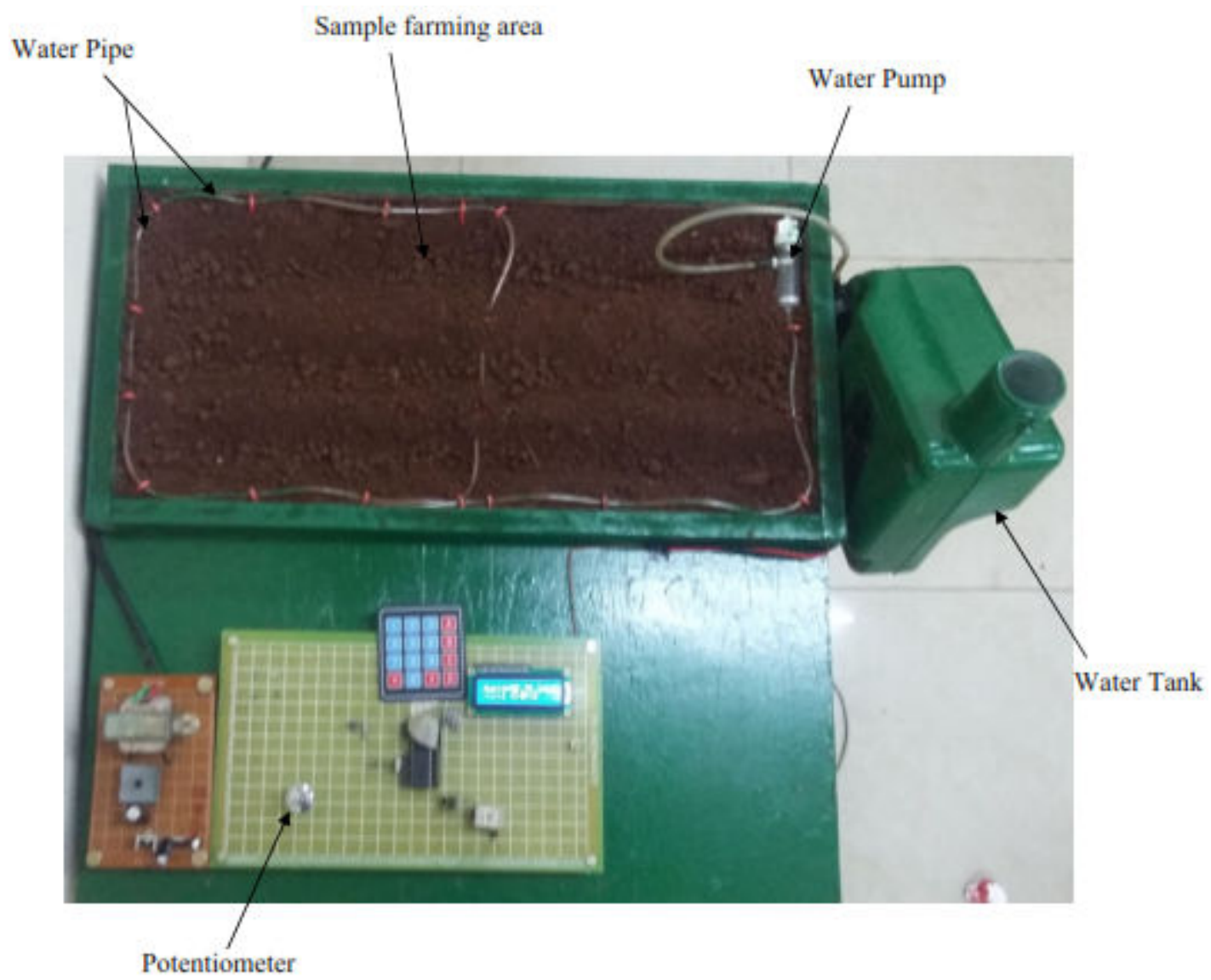

Figure 5: Physical implementation of the system

\section{CONCLUSION}

This proposed system controls the moisture level of the soil. The system is used to switch on/off the watering system through pump depending on the predefined set level of soil moisture. The control unit is a PIC16F877A microcontroller while the sensing component is a potentiometer. Based on the values given by the potentiometer, the microcontroller takes subsequent action and every process going on in the system displayed through LCD. The experimental result shows that both simulation and hardware implementation are working in a successful manner with a similar result. To further improve the effectiveness and efficiency of the system, it is possible to integrate GSM technology to give information and to report if a problem occurred to the concerned person, integrate the system with temperature and humidity sensors to monitor the weather conditions in the farm and integrate the $\mathrm{PH}$ value control mechanism.

\section{Conflict of Interest}

Authors declared no conflict of interest.

\section{REFERENCES}

Frehiwot Mulugeta (2009). Ethiopia Commodity Exchange Authority, Lentil Production, Supply, Demand and Marketing issues in Ethiopia.
Frehiwot Mulugeta (2010). Ethiopia Commodity Exchange Authority, Profile of Haricot bean production, supply, demand and marketing issues in Ethiopia.

Hachimenum Nyebuchi Amadi (2015). Effective Earthing System in the Corrosive Soil of Niger Delta. International Journal of Emerging Science and Engineering 3(6): 5-9.

Kotaiah Swamy, D., Rajesh, G., Jaya Krishna Pooja, M., Rama Krishna, A. (2013). Microcontroller Based Drip Irrigation System. International Journal of Emerging Science and Engineering 1(6):1-4.

Kumbhar, S.R., Arjun P. Ghatule (2013). Microcontroller based Controlled Irrigation System for Plantation" Proceedings of the International Multi Conference of Engineers and Computer Scientists, Vol II.

LCD Module (2012). LCD Module Data Sheet, [Available online: www.engineersgarage.com/electronic-components /16x2-Icd-module-datasheet, Accessed on June 24, 2015]

Semera (2010). Afar National Regional State Program of Plan on Adaptation to Climate Change.

Shiraz Pasha, B.R., Yogesha, B. (2014). Microcontroller Based Automated Irrigation System. International Journal of Engineering And Science 3(7): 6-9.

Umeh Maryrose, N., Mbeledogu Njideka, N., Okafor, S.O., Agba, F.C. (2015). Intelligent microcontroller-based irrigation system with sensors. American Journal of Computer Science and Engineering 2(1):1-4. 